\title{
THE EFFECT OF WATER SPRAY ON THE RELEASE OF COMPOSITE NANO-DUST
}

Stevan M. Cokic ${ }^{1}$, Christof Asbach², Jan De Munck ${ }^{1}$, Bart Van Meerbeek ${ }^{1}$, Peter Hoet ${ }^{3}$, Jin

Won $\mathrm{Seo}^{4}$, Kirsten L. Van Landuyt ${ }^{1}$

${ }^{1}$ KU Leuven BIOMAT, Department of Oral Health Sciences, University of Leuven \& Dentistry University Hospitals Leuven, Kapucijnenvoer 7, 3000 Leuven, Belgium

${ }^{2}$ Institute of Energy and Environmental Technology (IUTA) e.V., Bliersheimer Straße 60, 47229 Duisburg, Germany

${ }^{3}$ Occupational, Environmental and Insurance Medicine, KU Leuven, Kapucijnenvoer 35/5, B-3000 Leuven, Belgium

4 Surface and Interface Engineered Materials, Department of Materials Engineering, University of Leuven, Kasteelpark Arenberg 44, 3001 Heverlee, Belgium

*Corresponding author: Kirsten L. Van Landuyt, KU Leuven BIOMAT, Department of Oral Health Sciences, KU Leuven, Kapucijnenvoer 7, B-3000 Leuven, Belgium. TEL: +3216-33.27.85, FAX: +32-16-33.24.59, E-mail: kirsten.vanlanduyt@uzleuven.be

\section{ACKNOWLEDGMENTS}

This research was supported by the Research Foundation-Flanders (G.0884.13 and KAN2014 1.5.162.14). We would like to thank the manufacturers for generously providing the commercial composites.

\section{Declarations of interest}

Declarations of interest: none. 


\section{ABSTRACT}

Objective: To evaluate the collection efficiency of water spray on the release of airborne composite particles during grinding of composite materials.

Materials and Methods: Composite sticks (L:35mm x W:5.4mm x T:1.6mm) of seven commercial dental composites were ground with a rough diamond bur (grain size $100 \mu \mathrm{m}$, speed 200,000rpm). All experiments were performed in an enclosed $1 \mathrm{~m}^{3}$ chamber with low particulate background $\left(<1,000 \# / \mathrm{cm}^{3}\right)$ and airborne particles were evaluated based on their electrical mobility. The number size distribution was determined by scanning mobility particle sizer (SMPS). Particles were collected by electrostatic precipitator (ESP) and ultramorphologically and chemically analyzed by transmission electron microscope equipped with energy dispersive spectroscopy (TEM-EDX).

Results: SMPS measurements confirmed that both dry and wet grinding generated high concentrations of nanoparticles particles with the highest concentration recorded during the last minute of grinding $\left(1.80 \times 10^{6}\right.$ $\left.3.29 \times 10^{6} \# / \mathrm{cm}^{3}\right)$, after which a gradual decline in particle concentration took place. Nevertheless, grinding with water spray resulted in a significant reduction of the number of released particles $\left(5.6 \times 10^{5}-1.37 \times 10^{6} \# / \mathrm{cm}^{3}\right)$. The smallest particle diameter was recorded during the last minute of grinding followed by a continuous growth for every next measurement. TEM of composite dust revealed a high concentration of particles varying in both, size and shape.

Conclusions: Regardless of whether the water-cooling spray system was used during bur manipulation of composite materials, predominately nano-particles were released. However, the particle concentrations significantly decreased with water spray.

Clinical Relevance: Since water spray might not be sufficient in nanoparticle collection, special care should be taken to prevent inhalation of composite dust.

\section{KEYWORDS}

nano-particles, composite dust, fillers, SMPS, TEM-EDS 


\section{INTRODUCTION}

In the past years, the biocompatibility of composite materials has received increasingly more attention. So far, researchers have mainly focused on the toxicity of the leachable compounds, especially residual monomers, as in-vitro research revealed cytotoxic, genotoxic, mutagenic and estrogenic effects [1]. Apart from these wellknown toxic effects, some still unknown risks have lately come under scrutiny, such as the ones derived from nano-sized fillers, which are an unavoidable and at the same time necessary constituent of every type of composite [2].

Only recently, it has been shown that dental personnel and patients could unintentionally be exposed to these often still polymer-coated (nano-) particles during final steps of composite placement. During routine dental procedures such as removing, shaping or polishing composites, high concentrations of so-called "respirable dust" $(<4 \mu \mathrm{m})$ can be released in the breathing area of the dentist and the patient [3]. More specifically, particle characterization showed that the highest percentage of these released airborne particles belong to the group of nanoparticles (NP) $(<100 \mathrm{~nm})$, which can easily be inhaled and penetrate deeply into the lungs $[4,5]$. Ultramorphological TEM analysis showed that composite dust particles usually consisted of small pieces of composite containing mainly filler particles held together in the resin matrix, but also a certain number of single nanoparticles could be observed. Taking into consideration the unique physicochemical properties of NP, which are reflected in their small size, chemical composition, surface structure, solubility, shape and aggregation, nanoparticles could generate adverse biological effects in living cells, even when larger particles with the same chemical composition do not pose any toxicological hazard [6]. For instance, an increased frequency of respiratory hypersensitivity among dental personnel has been reported, but the real cause has not been determined yet [7].

In dental practice, it is advised to operate highspeed handpieces or turbines in combination with water spray in order to prevent temperature rises that could irreversibly damage the pulp or lead to composite debonding [8]. Unfortunately, certain practical limitations (for example using polishing disks) often do not allow working with water spray, thus forcing dentists to manipulate with composites without water cooling. Also, beside the important role of water cooling during rotary manipulation, it is believed that water can collect and agglomerate emitted particles during mechanical material manipulation [9]. However, information concerning a possible effect of water spray on the release of respirable dust is still scarce. 
The main objective of this study was to evaluate the effect of water spray during rotary manipulation of composites on the release of respirable, and in particular nano-sized dust. The null hypothesis of this study was that water spray does not have any influence on the number of particles and particle size of composite dust released during composite grinding. 


\section{MATERIALS AND METHODS}

\section{Sample preparation}

Seven commercial dental composites, including nano-hybrid and traditional hybrid composites, either paste-like or flowable, were included in this study. Their composition can be found in Table 1. For each composite, 9 sticks with a size of L:35 mm x W: $5.4 \mathrm{~mm} \times \mathrm{D}: 1.6 \mathrm{~mm}$ were prepared in a metal mold following a clinically relevant protocol according to the instructions of the manufacturer. Prior to polymerization, the composite material was covered with a glass plate, and light cured for $20 \mathrm{~s}$ with a light curing lamp (Bluephase 20i, High power mode Ivoclar-Vivadent, Schaan, Liechtenstein) with an output $>1000 \mathrm{~mW} / \mathrm{cm}^{2}$. Since the diameter of the lamp was much smaller than the length of the sample, each segment of the sample was polymerized for 40 sec until all parts were cured (approximately 5 curings per sample). Each time the lamp tip was held as close as possible to the covering glass plate.

Laboratory measurement of concentration and size of airborne nanoparticles released during grinding composites

The composite samples were then ground following a clinically relevant protocol in an enclosed $1 \mathrm{~m}^{3} \mathrm{chamber}$ with low background particle contamination $\left(<1,000 \# / \mathrm{cm}^{3}\right)$ and the released airborne particles were evaluated by the means of electrical mobility analysis (Fig. 1). The chamber was made from anti-static plexiglass with two openings at the side sealed with gloves, which enabled manipulation of the samples in the box. The sampling point was placed inside the chamber, near the grinding position and was connected through a flow splitter outside of chamber to (1) a scanning mobility particle sizer (SMPS; model 3938 with long differential mobility analyzer (DMA) 3081A and a UCPC, either water-based model 3787 or a butanol based model 3776; TSI, Shoreview, MN, USA) for measuring number size distributions of particles in a size range from $12.2 \mathrm{~nm}$ to $333.8 \mathrm{~nm}$ (SMPS settings: 0.3 1/min aerosol flow, 6 1/min sheath flow, scan time: $30 \mathrm{~s}, 3$ s retrace, restart every $60 \mathrm{~s}$ ), and to (2) an electrostatic precipitator (ESP) (Nanometer Aerosol Sampler NAS, TSI model 3089) for electron microscopic particle characterization. In order to enhance the collection efficiency, particles were charged upstream of the ESP, using a custom-made unipolar point-to-plate corona charger. The air withdrawn from the chamber by the measurement equipment was compensated for by HEPA filtered air to avoid excessive underpressure inside the chamber. A common 30 w household fan (AEG model VL5529, Kempen, Germany) ensured optimal and homogeneous spatial distribution of the airborne particles in the chamber. 
Manipulation of the specimens and the bur inside the experimental chamber $\left(1 \mathrm{~m}^{3}\right)$ was done using the sealed gloves. The composite sticks were held with a forceps during grinding with a rough bur (842314014 Komet, Lemgo, Germany, grain size $100 \mu \mathrm{m}$ ) in a Kavo intracompact handpiece connected to a micromotor (EWL K9, Kavo, Biberach, Germany) operated by compressed air. Measurements without composite grinding were performed and served as a negative control in order to determine the level of particle emission from the dental handpiece. Moreover, the motor was placed outside of the chamber so that unavoidable particle emission from the motor did not mix with the released composite dust particles during grinding. After each test, the experimental chamber was air-flushed using strong vacuum system attached to the chamber, in order to reduce the amount of particles back to $<1,000 \# / \mathrm{cm}^{3}$ before each measurement. For each test $(\mathrm{n}=3), 3$ composite sticks were ground, and particle size distributions were obtained. Each measurement was performed for 3 minutes during grinding and lasted for additional $10 \mathrm{~min}$. This sampling time was carefully set to prevent saturation of the grid with particles.

\section{Electron microscope particle characterization}

In the electrostatic precipitator (ESP), airborne dust was collected on formvar-coated copper grids. For each composite, two particle fractions were collected; (a) unclassified $(<1 \mu \mathrm{m})$ and size-classified particles, based on the size of the filler particles according to the manufacturer (Table 1). Particle size and shape was subsequently analyzed using the transmission electronic microscope (TEM) (Jeol, JEM-1200 EX II, Tokyo, Japan) and the origin of the particles was confirmed by evaluating their chemical composition by another transmission electron microscope (TEM, CM-200FEG, Philips, Eindhoven, The Netherlands) equipped with energy-dispersive x-ray analysis. The TEM was fitted with a field-emission gun and a super-twin lens operational up to $200 \mathrm{kV}$ acceleration voltage yielding a point to point resolution of $0.24 \mathrm{~nm}$ and a smallest probe size of $1 \mathrm{~nm}$.

\section{Statistical analysis}

In order to assess the particle number concentrations and the mean particle size of each evaluated composite, particle number concentrations, and particle diameter were fitted for each composite $(n=3)$ with the logtransformed time, using an exponential or a linear function in function in a (non-)linear mixed effects model and taking into account the individual tests as a random factor ( R 3.2.0 and nlme package, R Foundation for Statistical Computing, Vienna, Austria). From these models, relevant data (initial concentration, ...) were 
extracted and subjected to ANOVA analysis. Statistically predicted increase in particle diameter was determined by comparing two $95 \%$ confidence intervals for dry and wet grinding as individual factors.

\section{RESULTS}

Laboratory measurement of size and concentration of airborne nanoparticles released from grinding composite with and without water cooling

Particle number concentration

Statistical analysis of the SMPS data confirmed that both dry and wet grinding generated significantly higher concentrations of nanoparticles than the background concentration $\left(<1000 \# / \mathrm{cm}^{3}\right)$. The highest particle concentrations were observed during the last minute of sample grinding (Fig. 2, Supplemental Fig. 1), followed by a gradual decrease in particle concentration immediately after grinding. This sequence is caused by accumulation of the particle concentration inside the chamber during grinding and its decay thereafter. Concentrations without water spray were the highest, and ranged from $1.80 \times 10^{6}$ to $3.29 \times 10^{6} \# / \mathrm{cm}^{3}$. Grinding in combination with water spray reduced particle release approximately by half for all composites, and the particle concentrations ranged from $5.6 \times 10^{5}$ to $1.37 \times 10^{6} \# / \mathrm{cm}^{3}$. This effect of water spray on the release of NP was statistically significant.

Comparing NP release between the investigated composites, the nano-hybrid composite Herculite XRV Ultra in dry conditions emitted higher particle concentrations $\left(3.29 \times 10^{6} \# / \mathrm{cm}^{3}\right)$ than the other evaluated composites. The lowest particle concentration was released by Spectrum TPH3 and Durafil VS $\left(1.80\right.$ and $1.91 \times 10^{6} \# / \mathrm{cm}^{3}$, respectively). While using water spray, the highest particle concentration was recorded for Heliomolar flow $\left(1.37 \times 10^{6} \# / \mathrm{cm}^{3}\right)$ and the lowest concentration was released for Herculite XRV $\left(5.60 \times 10^{5} \# / \mathrm{cm}^{3}\right)($ Table 2 , Supplemental Table 1).

\section{Particle size distribution and average particle size}

The size distributions were polydisperse and unimodal for every composite, irrespective of the use of water spray (Fig. 3). SMPS revealed that all composites predominately produced nanoscale particles $(<100 \mathrm{~nm})$ with the mode value ranging from 30-50 $\mathrm{nm}$ for dry grinding and 20-30 $\mathrm{nm}$ for wet grinding. The smallest particles were observed during grinding. Subsequent measurements for the next 10 min showed a slight increase of particle size distribution, suggesting to a size growth due to agglomeration of the particles. 
The initial (first minute) and final (after $10 \mathrm{~min}$ ) average size for dry and wet grinding differed significantly. The initial average size ranged from $30-50 \mathrm{~nm}$ and $20-40 \mathrm{~nm}$ during dry and wet grinding respectively. The average size at the end of the measurements (after $10 \mathrm{~min}$ ), was 35-57 nm and 60-70 nm for dry and wet grinding respectively (Fig. 4, Supplemental Fig. 2).

The agglomeration tendency of the released particles could statistically be determined (Table 3). The agglomeration tendency, which was presented as a statistically predicted increase in particle diameter, was significantly higher during dry grinding compared to wet grinding for all tested composites except for Durafill VS where there was no statistical difference observed (Table 3). It ranged between $4.51-15.07 \mathrm{~nm}$ with the largest increase in size for Herculite XRV $(15.07 \mathrm{~nm})$ and Heliomolar flow $(14.13 \mathrm{~nm})$ and the smallest for Durafil VS $(4.51 \mathrm{~nm})$.

\section{Electron microscopy characterization}

TEM characterization of the unclassified fraction of composite dust revealed particles varying in both size and shape (Fig. 5 and 6). Their size ranged from $7 \mathrm{~nm}$ to $1 \mu \mathrm{m}$. Larger particles consisted of small pieces of composite material with fillers held together in resin matrix. Many particles were nano-sized ranging from $7 \mathrm{~nm}$ up to $60 \mathrm{~nm}$, which corresponds to the SMPS findings as well as with the filler information given by the manufacturer. Furthermore, single nano-sized filler particles could be observed, especially when the fractioned particles were evaluated. The presence of agglomerates and aggregates for all tested composites suggest that agglomeration also takes place upon collecting the particles on the grid. Larger particles were observed in the dry grinding group compared to wet grinding.

TEM-EDS showed that the composite dust particles from all composites featured peaks of Si and carbon together with some other characteristic elements (Table 4). Peaks representing $\mathrm{Zr}$ could be observed for Filtek Supreme XTE and Durafil VS, which may be attributed to spherical Si-Zr clusters. GrandioSO, Herculite XRV Ultra, Spectrum TPH3, Herculite XRV featured Ba and Al (GrandioSO) peaks, which could be attributed to barium-silica-(aluminum) glasses, that are often used together with $\mathrm{Zr}$ to improve the radio-opacity of the composite. A high $\mathrm{Cu}$ content was found in all samples, which stemmed from the TEM grid itself and not from the particles and was therefore omitted in Table 4. 


\section{DISCUSSION}

This is considered the first study to evaluate the influence of water spray on the release of airborne nanoparticles during bur manipulation of different types of dental composites. Our results corroborate previous findings that high concentrations of composite dust are released during bur manipulation of composites and that dental personnel could be exposed to airborne NP while working. However, now we demonstrated that the use of water spray during rotary manipulation can reduce the amount of released particles approximately by half [9]. Nevertheless, with an average concentration between $0.5-1 \times 10^{6}$, the release of particles with water spray was still much higher than the background particle concentration.

In our study we have tested seven different commercially available composites that represent various types of composite materials (nano-composite, microfilled, micro-hybrid, nano-hybrid; with either flowable or paste-like consistency). However, it has been shown that all different types of composites, regardless of their classification, contain a certain amount of nanoparticles $(<100 \mathrm{~nm})[10]$. The amount of filler particles packed inside the composite material determines their viscosity; flowable composites usually contain from 60-75 wt $\%$ and a pastelike composite can contain up to $85 \mathrm{wt} \%$ [11]. For that reason, dental composites are considered one of the most highly packed polymer materials with (nano-) particles (NP) in the material industry.

All our experiments were performed in a $1 \mathrm{~m}^{3}$ sealed cubic box which allowed us to measure particle release in the most standardized way. The dimensions of the box and a small fan inside prevented forced particle agglomeration and allowed homogenous particle distribution during measurements. Moreover, one of the largest challenges in release and/or exposure studies is the difficult differentiation between background emissions and particles emitted in the experiment [12-14]. Before each measurement, particles from the box were evacuated with a suction system and the background particle concentration was reduced to $<1,000 \# / \mathrm{cm}^{3}$ (typical indoor

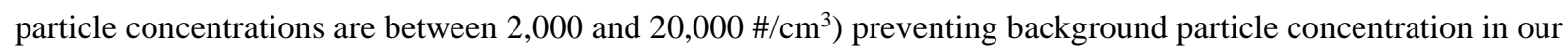
chamber to influence our measurements. Even though laboratory studies can never completely represent clinically relevant conditions, they can give insight and provide a valuable information on the potential nanoparticle exposure in the workplaces. Nowadays the most commonly used method to evaluate airborne submicron particle number concentrations as function of particle size, is based on electrical mobility analysis of the particles. While micron particles are large enough to scatter light so that they can be measured optically, particles smaller than $500 \mathrm{~nm}$ can only be classified by their electrical mobility or by inertial impaction [15]. 
These instruments normally consists of four main components: a pre-separator (removing of large particles), a particle charger (to establish a known particle charge distribution), a differential electrical mobility analyzer (DMA) and an instrument for the quantification of the mobility classified particle concentrations, e.g. a condensation particle counter (CPC) [16]. The most widely used instrument is the scanning mobility particle sizer (SMPS) which is characterized by a high particle size resolution. However, the main drawback of this method is that it takes at least $30 \mathrm{~s}$ to reliably measure a size distribution during which the aerosol has to be stable. More specifically, during first minutes of grinding the particle number concentration is rapidly changing which can lead to high variability of measurements. Moreover, this high variability is additionally influenced by low time resolution (1 min) of SMPS and its inability to cope with fast concentration and size changes which normally occur during until a particle concentration stability is obtained (Supplemental Fig. 1, Supplemental Fig. 2). Consequently, 3 composite sticks were ground during 3 min of active sampling to obtain three size distributions during grinding of each material. As every stick is larger than an average restoration, it is clear that in clinical situations, such large amounts of freshly polymerized composite are never ground (or polished) at once, and that the concentrations obtained in this experiment must be interpreted with care.

During tooth preparation or filling replacement, the primary function of cooling by water spray is decreasing the temperature of the bur to prevent irreversible thermal damage of the pulp [17]. Moreover, a relation has been observed between water spray characteristics (water spray patterns, number and positioning of channels) and cutting performance [18]. So far, water spray has not been considered as a possible way to prevent dust emission in dental practice even though this method is well known as an efficient dust collector in industries [19]. So far, four possible mechanisms of particle scavenging by water droplets have been described: impaction, interception, Brownian diffusion and electrostatic attraction [20]. Impaction occurs when the path of a particle is intercepted with a water droplet and this mechanism plays an essential role in collection of large airborne particles $(>5 \mu \mathrm{m})$. Interception, on the other hand, happens when the airstream carrying airborne particle passes close to a water droplet and its efficiency is directly proportional to the particle diameter and inversely proportional to the droplet diameter [20]. At the same time, Brownian diffusion, as a random movement of particles and electrostatic attraction, which depends on the particle charge, is considered responsible for a droplet-particle interaction and collection of small particles from the air [21]. Knowing that airborne composite dust consists of various particle sizes $(0.005-7 \mu \mathrm{m})$, with a highest percentage of the number concentration emitted as NP (Fig. 3), it is most likely that a combination of these four mechanisms play a role in their collection from the air. After collision 
with water droplets, particles will be removed by gravitational sedimentation of the droplets. Even though the first collision phase happens much faster than gravitational sedimentation, it is assumed that water spray can accelerate deposition process on the floor and the walls [22].

Moreover, some researchers have expressed a concern that particles released during restorative dental procedures can end up in the effluent of the dental office and if they are not collected by the particle separator subsequently into environment [23]. So far these separators are only available for amalgam waste [24], however, this does not include other types of particle waste including waste resin based composites [25]. It is widely known that after polymerization resin based composites can release residual unpolymerized monomers and BPA for a long period of time (up to 53 weeks) [26]. Moreover, just recently it has been confirmed that composite dust particles are also capable of releasing unpolymerized residual monomers and small amount of BPA in the environment [27]. This finding was explained by the fact that many particles consisted of filler particles that were still contained in resin. So far, it is not known whether composite particulate waste can cause adverse effects on the environment. Similar to previous research, dry grinding resulted in the release of predominately nano-scaled particles [3, 4] (Fig. 3), but the use of water spray significantly decreased particle number concentrations suggesting that this could be a good procedure for NP removal from the air. Furthermore, the released particles were statistically smaller compared to particles released during dry grinding, but they underwent agglomeration in a similar way (Fig. 4). These findings can be explained in different ways. It is known that (extremely) high temperatures during grinding can cause material evaporation. Upon cooling, the vapor supersaturates to generate new high concentrations of very small nanoparticles by nucleation [28-30]. In presence of already existing particles, the vapor can also condense onto their surfaces, which may have resulted in larger particles when composite is ground without water cooling [29]. Moreover, lower particle number concentrations decrease the agglomeration tendency. If there are more particles within an air volume, particles will collide more frequently, which results in larger particles due to agglomeration. There is also a possibility that the water spray in this study only collected larger particles, leaving the smaller NP behind, as there are studies showing that the size of the water droplets determines their collection efficiency [21]. Anyhow, even though average size of the particles is smaller with wet grinding, it is not expected that this has an important influence in terms of nano-toxicology [5]. The most striking finding of this study was that even 10 minutes after grinding, in both conditions (with and without water spray), the concentrations of released NP were still multiple times higher than the background concentration. 
Which means, that the majority of NP remain suspended in the air without rapid agglomeration and diameter enlargement.

It is noteworthy that determining threshold limit values (TLV) regarding the occupational exposure to particulate matter has never been an easy task and is performed by detailed examination of exposure - response relationship by expert groups through numerous epidemiological studies [31]. The American Conference of Governmental Industrial Hygienists (ACGIH) recommended setting threshold limit values for occupational exposure through the mass concentration metrics . However, this approach has been shown to be inapplicable for the NP exposure as they practically do not have any mass. Additional reasons behind this are that there are still a numerous technical challenges to overcome. Some of them include the lack of standardized instrumentation and sampling protocols for NP measurements [32], difficulties to reach a consensus on a metric system [33] for NP and lack of clear correlation of an exposure-response relationship [34]. Therefore, unfortunately there is still is no official legal binding framework concerning the specific limit of NP [35].From a toxicological point of view, the concern regarding the potential health risk related to the exposure to the NP is reflected in the their specific physico-chemical properties - their small size and corresponding large surface area. With the decrease of particle size, their surface area increases exponentially exposing more atoms at the surface with the higher average binding energy per atom [36]. This results in much stronger reactivity with biological structures compared to the material with the same chemical composition but larger in size. Even though it is not completely understood which mechanism lies behind the specific toxicity of NP, multiple in-vitro and in-vivo studies found a direct relationship between the large surface area and the production of ROS (reactive oxygen species) which can consequently lead to oxidative stress and activation of apoptosis, necrosis, inflammation, fibrosis, hypertrophy, metaplasia and carcinogenesis [37]. Another concern is possibility of NP to translocate after their inhalation and deposition in the respiratory system [38]. There is still much discussion in literature regarding the extent of pulmonary translocation, however, it might partially explain the relationship between exposure to ambient nanoparticles and cardiovascular events such as heart attack and cardiac rhythm disturbances [39]. Recently, it has become more clear that in particular the pulmonary inflammatory reaction in response to the inhalation of NP is responsible for cardiovascular disease and even increased mortality as shown in statistical analyses [40]. Ultra-morphological characterization by TEM confirmed our previous research that NP are released during composite bur manipulation, regardless of the type and composition (Fig. 5 and 6) [3, 4, 41]. By evaluating both 
unfractionated and size-fractionated particles, we were able not only to focus on all size ranges but also on single filler particles. Even though this method is not considered as quantitative, it is the only one which allows a definitive identification of nanomaterials, especially when it is combined with chemical analysis [12] (Table 4). Elemental analysis by EDS showed peaks of $\mathrm{Si}$ which confirmed presence of $\mathrm{SiO}_{2}$. Since silica is also known as one of the major natural particle composition in the environment, the presence of heavy elements such as $\mathrm{Zr}, \mathrm{Al}$, $\mathrm{Ba}$ or $\mathrm{Yb}$, which are usually added to composite material to improve radio-opacity, confirmed the origin of the collected particles on the TEM grid.

Last, in this study the preventive effect of an aspirator has not been assessed. In clinical practice, water spray during rotary procedures always is performed in conjunction with aspiration. Future research is necessary to evaluate the protective effect of aspiration against NP exposure.

\section{CONCLUSIONS}

Overall, this study revealed that, regardless of whether the water spray is used during bur manipulation of composites, predominately NP are released. However, water spray resulted in a significant decrease in the number of released NP, suggesting that applying water spray during abrasive composite procedures may be a good procedure to reduce exposure to airborne composite dust. Nevertheless, even with water spray, high concentrations of NP could be observed up until 10 minutes after material grinding, meaning that NP could remain in the air long after the dental procedure has been completed. Taking into account that released airborne particles, which can release methacrylate monomers [7], may pose an occupational hazard, future research should focus more on the protection measures from the composite dust.

\section{COMPLIANCE WITH ETHICAL STANDARDS}

Conflict of Interest: The authors declare that they have no conflict of interest.

Funding: This study was funded by the Research Foundation-Flanders (G.0884.13 and KAN2014 1.5.162.14).

Ethical approval: This article does not contain any studies with human participants or animals performed by any of the authors.

Informed consent: For this type of study, formal consent is not required. 
Page 14 


\section{REFERENCES}

1. Schweikl H, Spagnuolo G, Schmalz G (2006) Genetic and cellular toxicology of dental resin monomers. J. Dent. Res.

2. Jandt KD, Sigusch BW (2009) Future perspectives of resin-based dental materials. Dent Mater 25:10011006 . doi: 10.1016/j.dental.2009.02.009

3. Van Landuyt KL, Yoshihara K, Geebelen B, et al (2012) Should we be concerned about composite (nano-)dust? Dent Mater 28:1162-1170 . doi: 10.1016/j.dental.2012.08.011

4. Van Landuyt KL, Hellack B, Van Meerbeek B, et al (2014) Nanoparticle release from dental composites. Acta Biomater 10:365-374 . doi: 10.1016/j.actbio.2013.09.044

5. Oberdörster G, Oberdörster E, Oberdörster J (2005) Nanotoxicology: An emerging discipline evolving from studies of ultrafine particles. Environ Health Perspect 113:823-839 . doi: 10.1289/ehp.7339

6. Nel A, Xia T, Mädler L, Li N (2006) Toxic potential of materials at the nanolevel. Science 311:622-627 . doi: $10.1126 /$ science. 1114397

7. Piirilä P, Hodgson U, Estlander T, et al (2002) Occupational respiratory hypersensitivity in dental personnel. Int Arch Occup Environ Health 75:209-216 . doi: 10.1007/s00420-001-0302-4

8. Cavalcanti BN, Otani C, Rode SM (2002) High-speed cavity preparation techniques with different water flows. J Prosthet Dent 87:158-61 . doi: http://dx.doi.org/10.1067/mpr.2002.120655

9. Akbar-Khanzadeh F, Milz S, Ames A, et al (2007) Crystalline silica dust and respirable particulate matter during indoor concrete grinding - wet grinding and ventilated grinding compared with uncontrolled conventional grinding. J Occup Environ Hyg 4:770-9 . doi: 10.1080/15459620701569708

10. Ferracane JL (2011) Resin composite - State of the art. Dent Mater 27:29-38 . doi: 10.1016/j.dental.2010.10.020

11. Randolph LD, Palin WM, Leloup G (2016) Filler characteristics of modern dental resin composites and their influence on physico-mechanical properties. Dent Mater 1-14 . doi: 10.1016/j.dental.2016.09.034

12. Kuhlbusch TA, Asbach C, Fissan H, et al (2011) Nanoparticle exposure at nanotechnology workplaces: A review. Part Fibre Toxicol 8:22 . doi: 10.1186/1743-8977-8-22 
13. Aitken RJ, Galea KS, Tran CL, Cherrie JW (2009) Workplace Exposure to Nanoparticles. Environ Hum Heal Impacts Nanotechnol 307-356 . doi: 10.1002/9781444307504.ch8

14. Ding Y, Kuhlbusch TAJ, Van Tongeren M, et al (2017) Airborne engineered nanomaterials in the workplace - a review of release and worker exposure during nanomaterial production and handling processes. J Hazard Mater 322:17-28 . doi: 10.1016/j.jhazmat.2016.04.075

15. Of S, Lifecycle AT (2014) Safety of Nanomaterials along Their Lifecycle

16. 15900:2009 I (2002) Determination of particle size distribution - Diferential electrical mobility analysis for aerosol particles. Shock 2009:1-8

17. Siegel SC, von Fraunhofer JA (2002) The effect of handpiece spray patterns on cutting efficiency. J Am Dent Assoc 133:184-188 . doi: 10.14219/jada.archive.2002.0142

18. von Fraunhofer JA, Siegel SC, Feldman S (2000) Handpiece coolant flow rates and dental cutting. Oper Dent 25:544-548

19. Kissel FN (2003) Handbook for Dust Control in Mining (IC 9465). 1-131

20. Ha TH, Nishida O, Fujita H, Harano W (2009) Prediction for Diesel Particulate Matter (DPM)

Collection Efficiency of Electrostatic Water Spraying Scrubber. J Japan Inst Mar Eng Eng. doi: $10.5988 /$ jime. 44.808

21. Kim HT, Jung CH, Oh SN, Lee KW (2001) Particle Removal Efficiency of Gravitational Wet Scrubber Considering Diffusion, Interception, and Impaction. Environ. Eng. Sci. 18:125-136

22. Gaunt LF, Hughes JF, Harrison NM (2003) Removal of domestic airborne dust particles by naturally charged liquid sprays. J Electrostat 58:159-169 . doi: 10.1016/S0304-3886(03)00044-5

23. Schmalz G, Hickel R, van Landuyt KL, Reichl FX (2018) Scientific update on nanoparticles in dentistry. Int Dent J 68:299-305 . doi: 10.1111/idj.12394

24. Jokstad A, Fan PL (2006) Amalgam waste management. Int. Dent. J.

25. Schmalz G, Hickelb R, Landuyt KL van, Franz-Xaver Reichl (2017) Nanoparticles in dentistry. Dent Mater 33:1110-1126 . doi: 10.1016/j.dental.2017.07.002

26. Putzeys E, Nys S De, Cokic SM, et al (2019) Long-term elution of monomers from resin-based dental Page 16 
composites. Dent Mater 35:477-485 . doi: 10.1016/j.dental.2019.01.005

27. Cokic SM, Duca RC, Godderis L, et al (2017) Release of monomers from composite dust. J Dent 60:5662 . doi: 10.1016/j.jdent.2017.02.016

28. Gómez V, Irusta S, Balas F, Santamaria J (2013) Intense generation of respirable metal nanoparticles from a low-power soldering unit. J Hazard Mater 256-257:84-89 . doi: 10.1016/j.jhazmat.2013.03.067

29. Fonseca AS, Viana M, Querol X, et al (2015) Ultrafine and nanoparticle formation and emission mechanisms during laser processing of ceramic materials. J Aerosol Sci 88:48-57 . doi: 10.1016/j.jaerosci.2015.05.013

30. Curwin B, Bertke S (2011) Exposure characterization of metal oxide nanoparticles in the workplace. J Occup Environ Hyg 8:580-587 . doi: 10.1080/15459624.2011.613348

31. Heal MR, Kumar P, Harrison RM (2012) Particles, air quality, policy and health. Chem Soc Rev 41:6606 . doi: 10.1039/c2cs35076a

32. Asbach C, Kaminski H, Fissan H, et al (2009) Comparison of four mobility particle sizers with different time resolution for stationary exposure measurements. J Nanoparticle Res 11:1593-1609 . doi: $10.1007 / \mathrm{s} 11051-009-9679-\mathrm{x}$

33. Cauda EG, Ku BK, Miller AL, Barone TL (2012) Toward developing a new occupational exposure metric approach for characterization of diesel aerosols. Aerosol Sci Technol 46:1370-1381 . doi: $10.1080 / 02786826.2012 .715781$

34. Sayes CM, Reed KL, Warheit DB (2007) Assessing toxicology of fine and nanoparticles: Comparing in vitro measurements to in vivo pulmonary toxicity profiles. Toxicol Sci 97:163-180 . doi: 10.1093/toxsci/kfm018

35. Maynard AD, Aitken RJ (2007) Assessing exposure to airborne nanomaterials: Current abilities and future requirements. Nanotoxicology 1:26-41 . doi: 10.1080/17435390701314720

36. Roduner E (2006) Size matters: why nanomaterials are different. Chem Soc Rev 35:583 . doi: $10.1039 / \mathrm{b} 502142 \mathrm{c}$

37. Arora S, Rajwade JM, Paknikar KM (2012) Nanotoxicology and in vitro studies: The need of the hour. 
Toxicol Appl Pharmacol 258:151-165 . doi: 10.1016/j.taap.2011.11.010

38. Hagens WI, Oomen AG, de Jong WH, et al (2007) What do we (need to) know about the kinetic properties of nanoparticles in the body? Regul Toxicol Pharmacol 49:217-229 . doi:

10.1016/j.yrtph.2007.07.006

39. Nemmar A, Hoylaerts MF, Hoet PHM, Nemery B (2004) Possible mechanisms of the cardiovascular effects of inhaled particles: Systemic translocation and prothrombotic effects. In: Toxicology Letters. pp $243-253$

40. Scheers H, Jacobs L, Casas L, et al (2015) Long-Term Exposure to Particulate Matter Air Pollution Is a Risk Factor for Stroke: Meta-Analytical Evidence. Stroke 46:3058-3066 . doi: 10.1161/STROKEAHA.115.009913

41. Chen M-H (2010) Update on dental nanocomposites. J Dent Res 89:549-560 . doi: $10.1177 / 0022034510363765$ 


\section{FIGURE CAPTIONS}

Fig. 1: Test set-up.

Abbreviations: DMA: Differential mobility analyzer; ESP: Electrostatic precipitator; FMPS: Fast mobility particle sizer; SMPS: Scanning mobility particle sizer

Fig. 2: The mean particle concentration for each composite as determined by SMPS. Wet grinding reduces the number of particles approximately by half. Over time, the concentration of particles decreased, but even after 10 minutes still high number concentrations were observed.

Fig. 3: Representative SMPS graph for GrandioSO, showing a unimodal distribution of the particles during composite grinding with (a) and without water cooling (b). It is clear that agglomeration takes place, as the modal peak shifts to the right. The amount of particles released upon wet grinding is significantly reduced compared to dry grinding. The number concentration of particles decreases over time (every measurement takes 1 minute). The distributions for the other composites (not shown) displayed a similar pattern over time.

Fig. 4: The mean particle size for each composite as determined by SMPS. Particle size was significantly lower when water spray was used, and increased over time due to agglomeration.

Fig. 5: Ultra-morphological analysis of respirable particles during composite grinding without water spray. Whereas mainly large particles could be observed on the TEM grids with the non-classified fraction of composite dust, mostly ultrafine particles could be seen for the classified fraction. Interestingly, these very fine particles often agglomerated on the grid, especially if there were folds in the formvar film covering the cupper grid.

Fig. 6: Ultra-morphological analysis of respirable particles during composite grinding with water spray. Similar observations were done as shown in Fig. 5, but particles tended to be smaller compared the dust captured during wet grinding.

Supplemental Fig. 1: Representative graph the mean particle concentration for GrandioSO as determined by SMPS.

Supplemental Fig. 2: Representative graph the mean particle size for GrandioSO as determined by SMPS. 


\section{FIGURES}

Fig. 1:

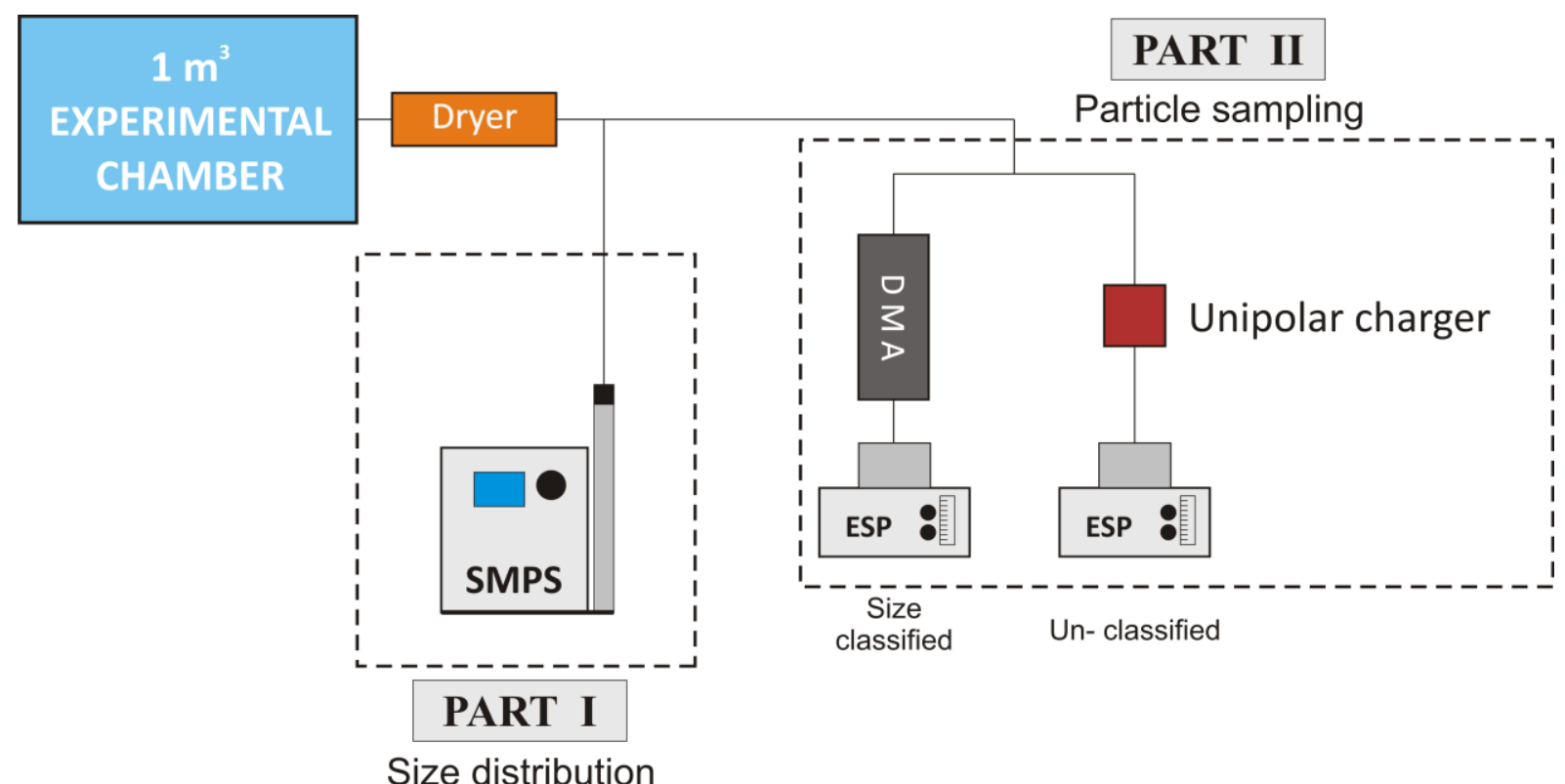


Fig. 2:

a Filtek Supreme XTE

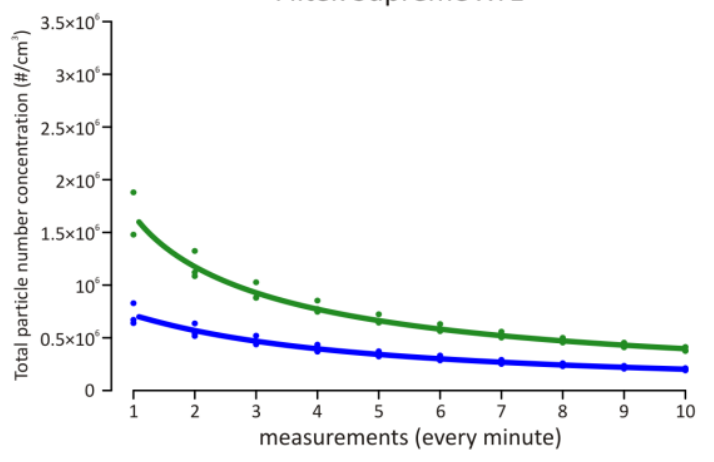

Without water cooling

C

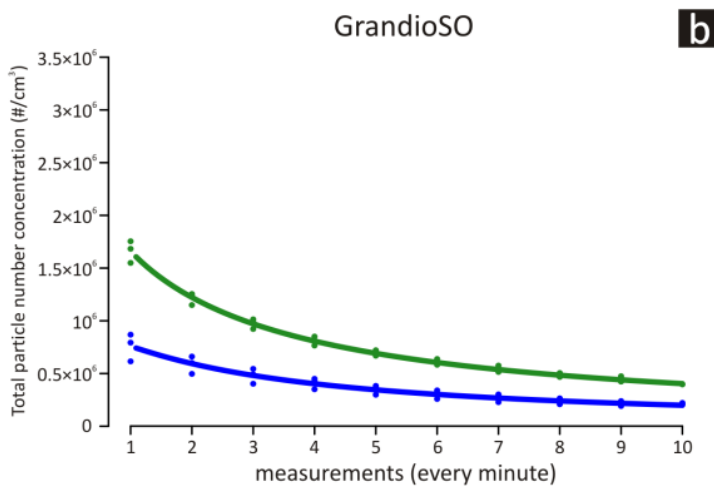

b Herculite XRV Ultra

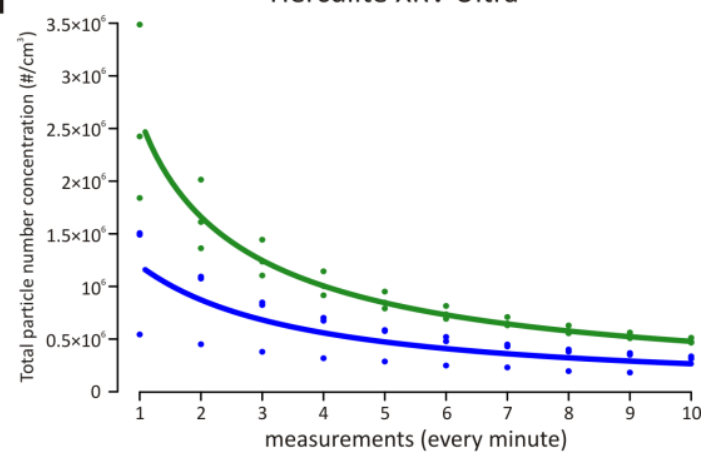

d

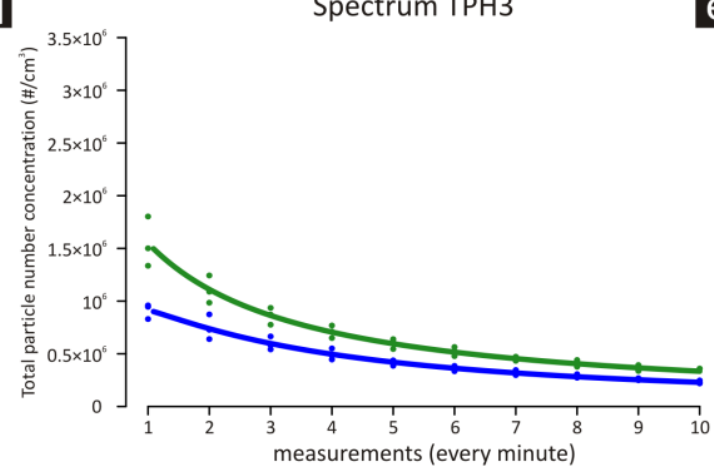

f

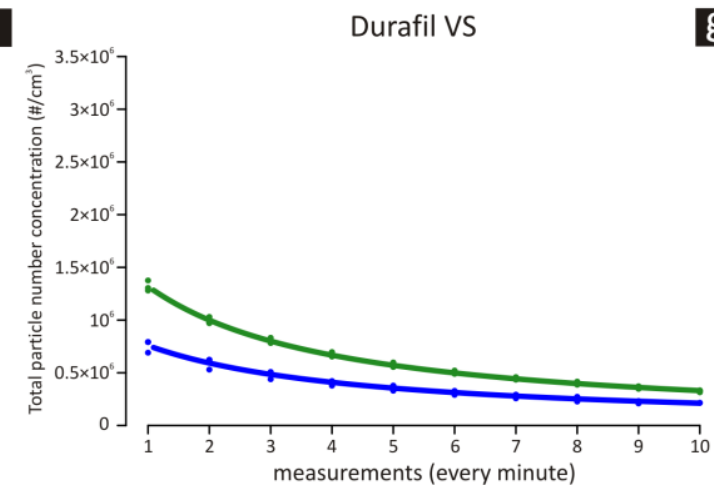

e

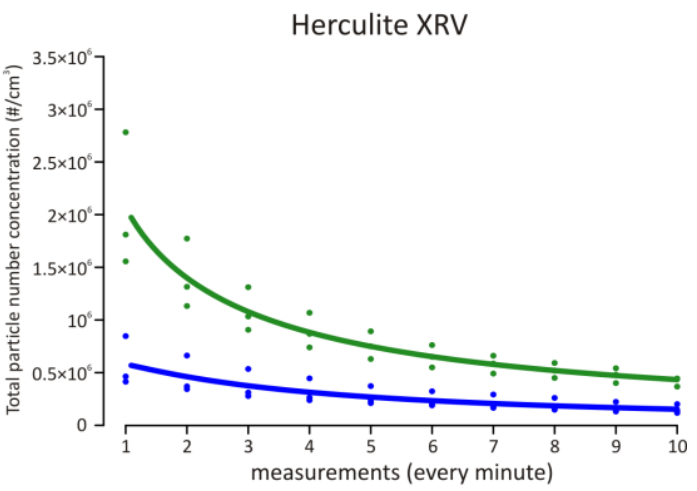

g

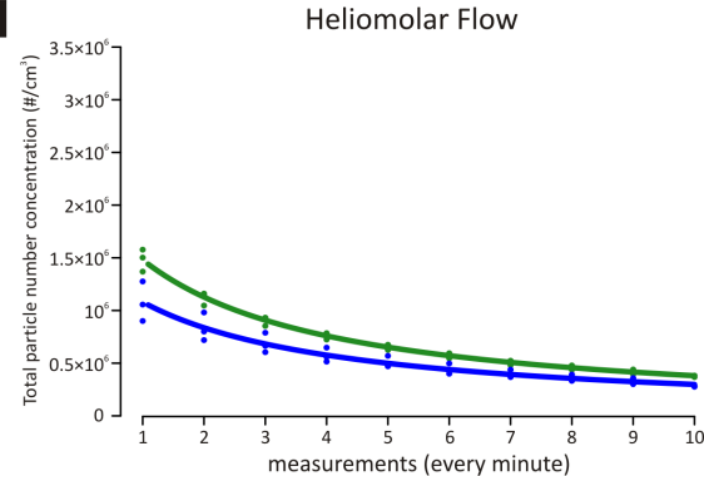


Fig. 3:

a

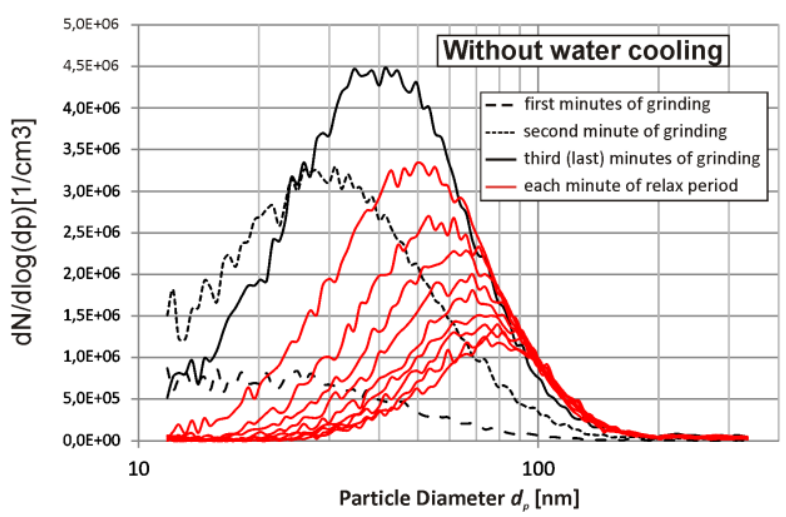

b

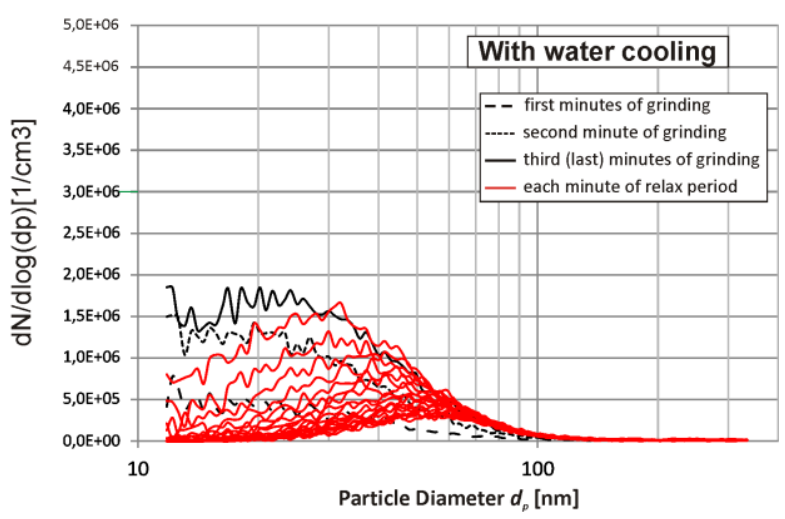


Fig. 4:

a

Filtek Supreme XTE

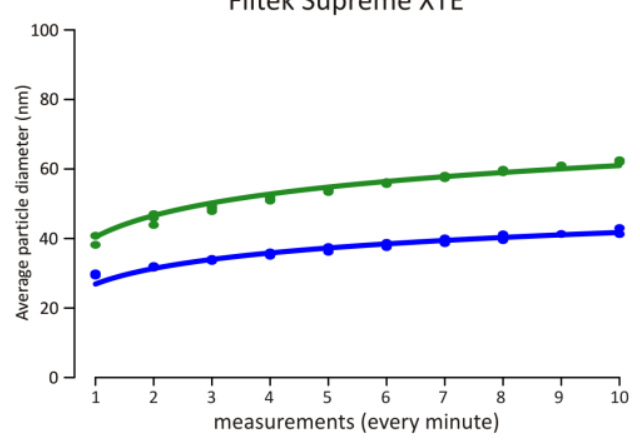

Without water cooling

- With water cooling

b

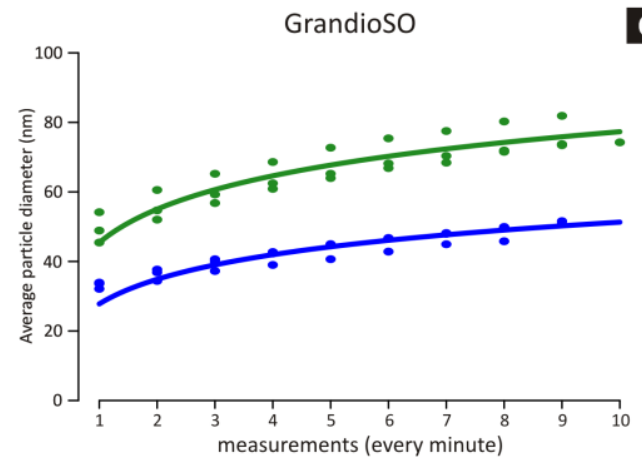

d

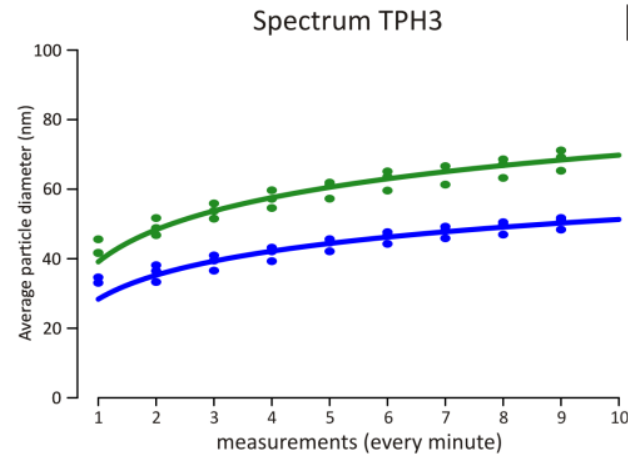

Durafil VS

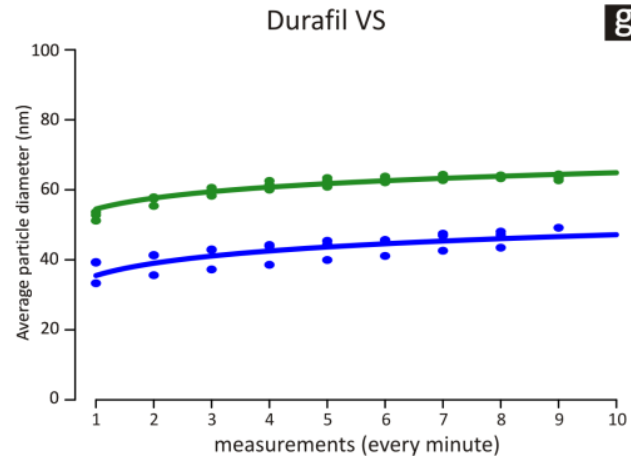

c

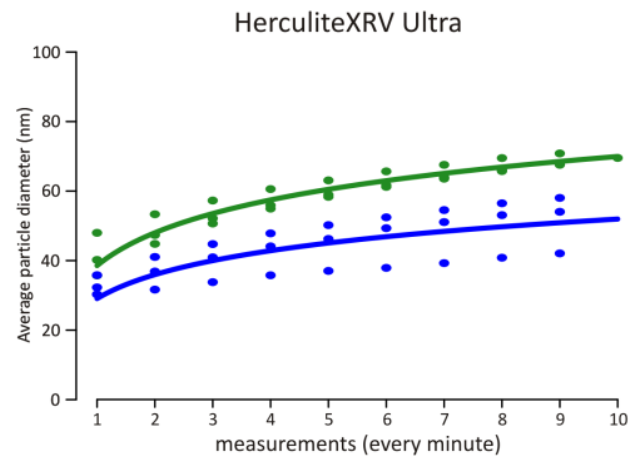

e

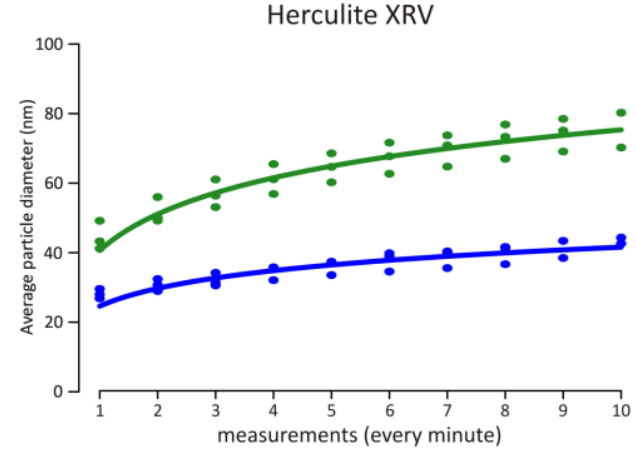

g

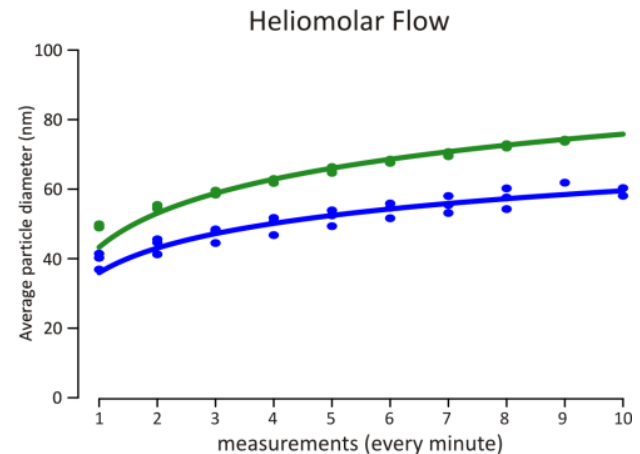




\section{Supplemental Fig. 1:}

\section{GrandioSO}
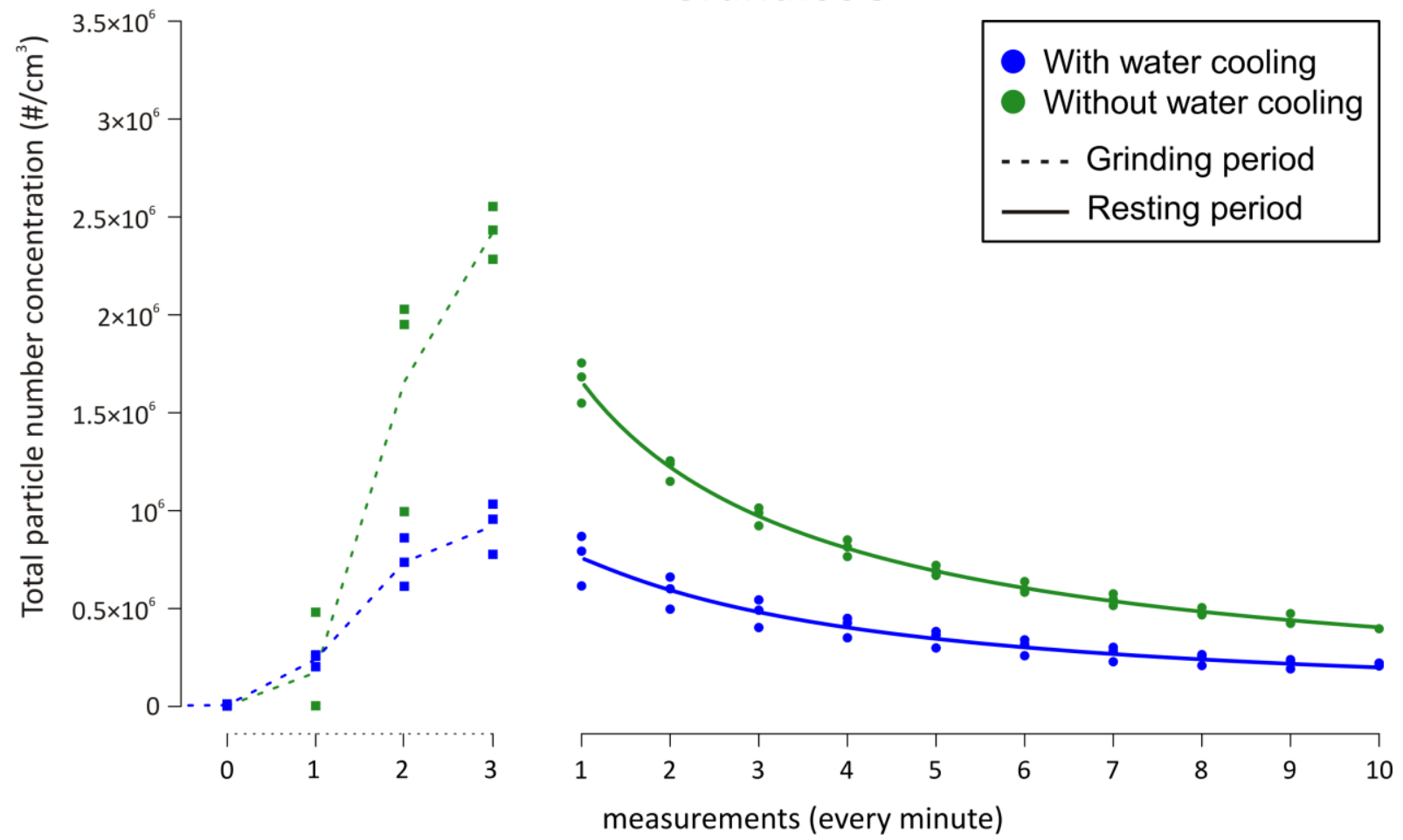


\section{Supplemental Fig. 2:}

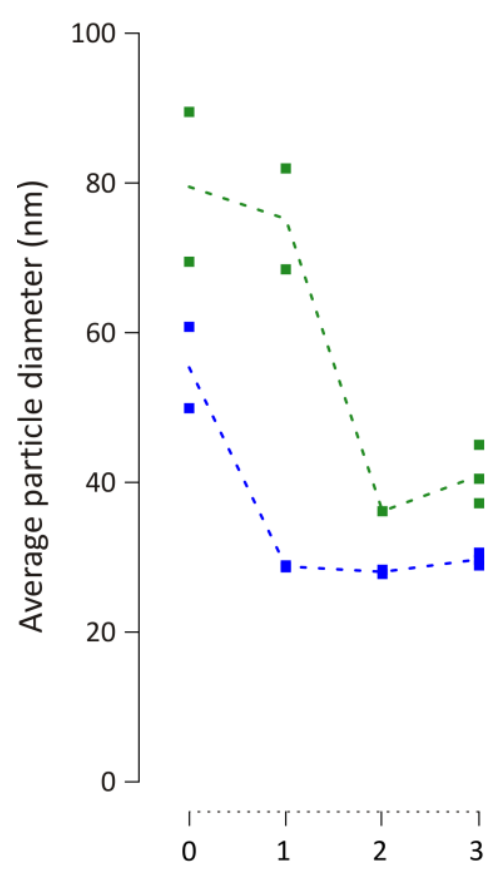

GrandioSO

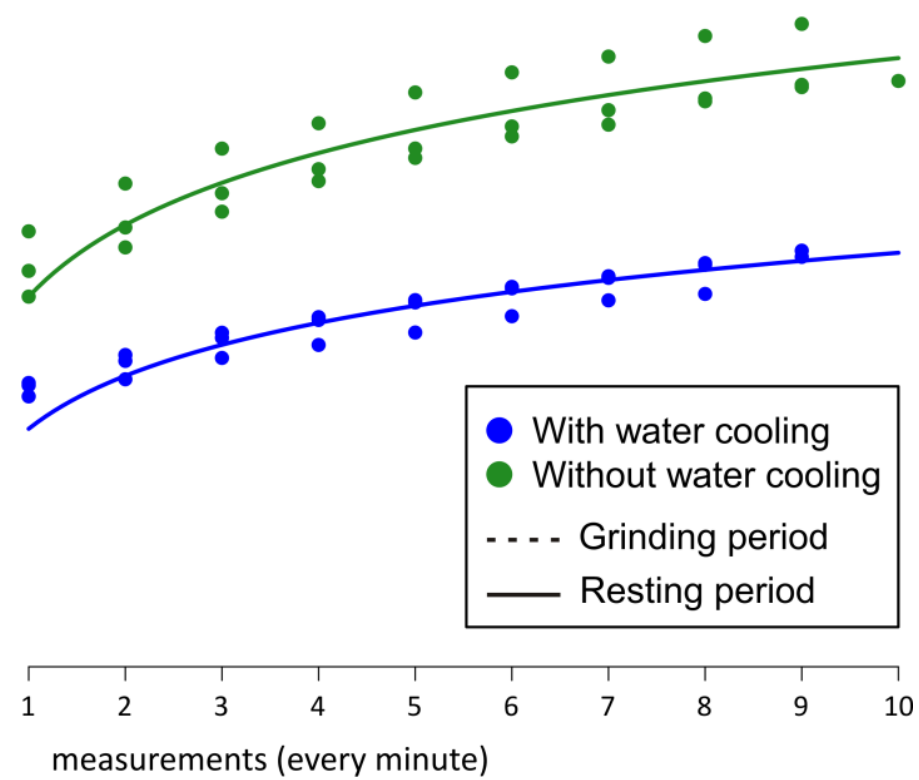




\section{TABLES}

\section{Table 1: Composition of the dental composites}

\begin{tabular}{|c|c|c|c|c|c|}
\hline Composite & Manufacturer & Classification & Resin matrix & Filler & Filler loading \\
\hline Filtek Supreme XTE & $\begin{array}{l}\text { 3M ESPE, Seefeld, } \\
\text { Germany }\end{array}$ & Nano-filled composite & $\begin{array}{l}\text { BisGMA, Bis-EMA, } \\
\text { UDMA, TEGDMA }\end{array}$ & $\begin{array}{ll}\text { - } & \mathrm{SiO}_{2}(20 \mathrm{~nm}) \\
\text { - } & \mathrm{Zirconia-silica} \text { clusters }(0.6-1.4 \mu \mathrm{m}) \text { with } \\
& \text { primary particles of }(5-20 \mathrm{~nm})\end{array}$ & $\begin{array}{l}78.5 \mathrm{wt} \% \\
59.5 \mathrm{vol} \%\end{array}$ \\
\hline GrandioSO & $\begin{array}{l}\text { VOCO, Cuxhaven, } \\
\text { Germany }\end{array}$ & Nano-hybrid composite & BisGMA, TEGDMA & - $\quad$ Spherical $\mathrm{SiO}_{2}$ nanoparticles $(20-50 \mathrm{~nm})$ & $\begin{array}{l}87 \mathrm{wt} \% \\
71.4 \text { vol\% }\end{array}$ \\
\hline Herculite XRV Ultra & Kerr Co, CA, USA & Nano-hybrid composite & $\begin{array}{l}\text { Methacrylate ester } \\
\text { monomers (TEGDMA } \\
\text { based on MSDS) }\end{array}$ & $\begin{array}{ll}\text { - } & \text { Barium glass }(0.4 \mu \mathrm{m}) \\
\text { - } & \mathrm{SiO}_{2}(20-50 \mathrm{~nm}) \\
\text { - } & \text { Pre-polymerized filler } \\
\end{array}$ & $78 \mathrm{wt} \%$ \\
\hline Spectrum ТРH3 & $\begin{array}{l}\text { Dentsply Caulk, } \\
\text { Konstanz, Germany }\end{array}$ & $\begin{array}{l}\text { Micromatrix with } \\
\text { nanotechnology }\end{array}$ & $\begin{array}{l}\text { BisGMA Adduct, } \\
\text { TEGDMA, BisEMA }\end{array}$ & $\begin{array}{ll}\text { - } & \text { Ba-Al-B-silicate glass }(<1.5 \mu \mathrm{m}) \\
\text { - } & \text { Ba-F-Al-B-silicate glass }(<1 \mu \mathrm{m}) \\
\text { - } & \mathrm{SiO}_{2}(10-20 \mathrm{~nm})\end{array}$ & $\begin{array}{l}57 \text { vol\% } \\
77 \mathrm{wt} \%\end{array}$ \\
\hline Herculite XRV & Kerr Co, CA, USA & Microhybrid & $\begin{array}{l}\text { Methacrylate ester } \\
\text { monomers (TEGDMA } \\
\text { based on MSDS) }\end{array}$ & - $\quad 0.6 \mu \mathrm{m}$ average particle size & $\begin{array}{l}79 \mathrm{wt} \% \\
59 \mathrm{vol} \%\end{array}$ \\
\hline Durafil VS & $\begin{array}{l}\text { Heraeus Kulzer Inc. } \\
\text { Irvine, CA }\end{array}$ & $\begin{array}{l}\text { Microfilled anterior } \\
\text { composite }\end{array}$ & $\begin{array}{l}\text { BisGMA, TEGDMA, } \\
\text { UDMA, PEGDMA, } \\
\text { BisEMA }\end{array}$ & $\begin{array}{ll}\text { - } & \mathrm{ZrO}_{2}(4-11 \mathrm{~nm}) \\
\text { - } & \mathrm{SiO}_{2}(20 \mathrm{~nm}) \\
\text { - } & \mathrm{SiO}_{2}-\mathrm{ZrO}_{2} \text { clusters }(0.6-10 \mu \mathrm{m}) \\
\text { - } & \text { Splinter polymer }(<20 \mu \mathrm{m})\end{array}$ & 66 vol\% \\
\hline Heliomolar Flow & $\begin{array}{l}\text { Ivoclar Vivadent AG, } \\
\text { Schaan Liechtenstein }\end{array}$ & Microfill, flowable & $\begin{array}{l}\text { BisGMA, } \\
\text { TEGDMA, } \\
\text { UDMA, }\end{array}$ & $\begin{array}{l}\text { - } \mathrm{SiO}_{2}, \text { Ytterbium trifluoride, Prepolymer } \\
(0.04-0.2 \mu \mathrm{m})\end{array}$ & $\begin{array}{l}51 \mathrm{wt} \% \\
30 \mathrm{vol} \%\end{array}$ \\
\hline
\end{tabular}


Abbreviations: BisEMA: ethoxylated bisphenol A glycol dimethacrylate; BisGMA: bisphenol A diglycidyl dimethacrylate; TEGDMA: triethylene glycol dimethacrylate, UDMA: urethane dimethacrylateBased on information provided by the manufacturer 
Table 2: Average particle number concentration during grinding

\begin{tabular}{lll}
\hline Composite material & $\begin{array}{l}\text { Number concentration without } \\
\text { water }\left[\# / \mathbf{c m}^{3}\right]\end{array}$ & $\begin{array}{l}\text { Number concentration with } \\
\text { water }\left[\# / \mathbf{c m}^{3}\right]\end{array}$ \\
\hline Filtek Supreme & $2.34 \mathrm{E}+06^{\mathrm{abc}}( \pm 2,11 \mathrm{E}+05)$ & $8.93 \mathrm{E}+05^{\mathrm{bcd}}( \pm 9,71 \mathrm{E}+04)$ \\
GrandioSO & $2.36 \mathrm{E}+06^{\mathrm{abc}}( \pm 1,05 \mathrm{E}+05)$ & $9.22 \mathrm{E}+05^{\mathrm{abcd}}( \pm 1,32 \mathrm{E}+05)$ \\
Herculite XRV Ultra & $3.29 \mathrm{E}+06^{\mathrm{a}}( \pm 3,29 \mathrm{E}+05)$ & $1.14 \mathrm{E}+06^{\mathrm{abc}}( \pm 5,51 \mathrm{E}+05)$ \\
Spectrum TPH3 & $1.80 \mathrm{E}+06^{\mathrm{c}}( \pm 1,98 \mathrm{E}+05)$ & $7.71 \mathrm{E}+05^{\mathrm{bcd}}( \pm 1,92 \mathrm{E}+05)$ \\
Herculite XRV & $2.62 \mathrm{E}+06^{\mathrm{ab}}( \pm 2,28 \mathrm{E}+05)$ & $5.60 \mathrm{E}+05^{\mathrm{d}}( \pm 1,59 \mathrm{E}+05)$ \\
Durafil VS & $1.91 \mathrm{E}+06^{\mathrm{c}}( \pm 1,03 \mathrm{E}+05)$ & $1.02 \mathrm{E}+06^{\mathrm{abc}}( \pm 9,92 \mathrm{E}+04)$ \\
Heliomolar flow & $2.23 \mathrm{E}+06^{\mathrm{bc}}( \pm 2,12 \mathrm{E}+05)$ & $1.37 \mathrm{E}+06^{\mathrm{a}}( \pm 3,75 \mathrm{E}+05)$ \\
\hline
\end{tabular}

Average particle number concentration and standard deviation (in brackets);

Different superscript letters depicts significant difference between composites 
Table 3: Agglomeration tendencies

\section{Without water}

\section{With water}

\begin{tabular}{l|cc|cc} 
Composite material & $\begin{array}{c}\text { Average particle } \\
\text { diameter - last } \\
\text { minute of grinding } \\
{[\mathrm{nm}]}\end{array}$ & $\begin{array}{c}\text { Statistically } \\
\text { predicted increase in } \\
\text { particle diameter } \\
{[\mathrm{nm}]}\end{array}$ & $\begin{array}{c}\text { Average particle } \\
\text { diameter - last minute } \\
\text { of grinding } \\
{[\mathrm{nm}]}\end{array}$ & $\begin{array}{c}\text { Statistically } \\
\text { predicted increase } \\
\text { in particle diameter } \\
{[\mathrm{nm}]}\end{array}$ \\
\hline Filtek Supreme XTE & 40,41 & 8,93 & 26,90 & $6,45^{*}$ \\
GrandioSO & 45,44 & 13,84 & 27,79 & $10,21^{*}$ \\
Herculite XRV Ultra & 38,56 & 13,63 & 29,08 & $9,94^{*}$ \\
Spectrum TPH3 & 39,10 & 13,32 & 28,37 & $9,96^{*}$ \\
Herculite XRV & 40,63 & 15,07 & 24,62 & $7,37^{*}$ \\
Durafil VS & 54,51 & 4,51 & 35,50 & 5,07 \\
Helliomolar flow & 43,27 & 14,13 & 35,95 & $10,24^{*}$
\end{tabular}

* statistically significant lower predicted increase in particle diameter compared to dry grinding. 
Table 4: Elemental analysis by TEM-EDS of the particles captured on the TEM grids during composite sample preparation

\begin{tabular}{ll}
\hline Composite material & EDS \\
\hline Filtek Supreme XTE & $\mathrm{Si}, \mathrm{Zr}$ \\
\hline GrandiSO & $\mathrm{Si}, \mathrm{Al}, \mathrm{Ba}$ \\
\hline Herculite XRV Ultra & $\mathrm{Si}, \mathrm{Ba}$ \\
\hline Spectrum TPH3 & $\mathrm{Si}, \mathrm{Ba}$ \\
\hline Herculite XRV & $\mathrm{Si}, \mathrm{Ba}$ \\
\hline Durafil VS & $\mathrm{Si}, \mathrm{Zr}$ \\
\hline Heliomolar flow & $\mathrm{Si}, \mathrm{Yb}$ \\
\hline
\end{tabular}

